\title{
DECOMPOSIÇÃO DA SERAPILHEIRA FOLIAR E RESPIRAÇÃO EDÁFICA EM UM REMANESCENTE DE CAATINGA NA PARAÍBA ${ }^{1}$
}

\author{
Alan Cauê Holanda ${ }^{2}$, Ana Lícia Patriota Feliciano³, Luiz Carlos Marangon ${ }^{3}$, Fernando Jose Freire e $^{3}$ \\ Enio Mizael Holanda ${ }^{4}$
}

\begin{abstract}
Resumo - A serapilheira é uma das principais fontes de transferência de nutrientes para o solo, assumindo preponderância no processo de ciclagem de nutrientes em ecossistemas florestais. O trabalho teve por objetivo analisar a decomposição de uma mistura foliar de 10 espécies da Caatinga, em paralelo com a respiração edáfica. O estudo foi realizado no Sítio Riachão, localizado no Município de Pombal, PB. A taxa de decomposição foi determinada por medidas de perda de massa, com o auxílio de sacolas de náilon (288) que continham $10,0 \mathrm{~g}$ de folhas das espécies. A respiração edáfica foi mensurada através da liberação de $\mathrm{CO}_{2}$ com o auxílio de baldes plásticos durante turnos de $24 \mathrm{~h}$. As coletas foram realizadas a intervalos de 45 dias. Ao longo de um ano de avaliação, foram decompostos $67 \%$ do material foliar. A respiração edáfica foi mais intensa no período noturno e em períodos em que houve maiores precipitações pluviométricas. A relação $\mathrm{C} / \mathrm{N}$ foi relativamente baixa, indicativo de maior taxa de mineralização. A precipitação pluviométrica e outras variáveis ambientais são importantes fenômenos que influenciam a atividade dos microrganismos no solo, fazendo que se torne mais intensa a decomposição da serapilheira.
\end{abstract}

Palavras-chave: Litterbags; Nutrientes; Savana estépica.

\section{LEAF LITTER DECOMPOSITION AND SOIL RESPIRATION IN A REMNANT OF THE CAATINGA IN THE STATE OF PARAÍBA}

\begin{abstract}
The litter is a major source of nutrients transfer to the soil, taking precedence in the process of nutrient cycling in forest ecosystems. The study aims to analyze decomposing of mixture of ten species of Caatinga in parallel with the soil respiration. The study was conducted at farm Riachão, located in the municipality of Pombal, PB. The rate of decomposition was determined by measurements of weight loss, with the aid of nylon bags (288) containing $10.0 \mathrm{~g}$ of leaves of the species. The soil respiration was measured through the release of $\mathrm{CO}_{2}$ with the aid of plastic buckets for 24-hour shifts. Samples were collected every 45 days. Over a year of the study, 67\% of leaf material was decomposed. The soil respiration was more intense at night and during periods where there was more rainfall. The C/N rate is relatively low, indicating a higher rate of mineralization. The rainfall and other environmental variables are important phenomena that influence the activity of microorganisms in the soil, causing a more intense decomposition of litter.
\end{abstract}

Keywords: Litterbags; Nutrient; Steppic savanna.

\footnotetext{
${ }^{1}$ Recebido em 01.11.2012 aceito para publicação em 02.02.2015.

${ }^{2}$ Universidade Federal Rural do Semi Árido, Departamento de Ciências Vegetais, Mossoró, Rio Grande do Norte, Brasil. E-mail: <alan.holanda@ufersa.edu.br>.

${ }^{3}$ Universidade Federal Rural do Pernambuco, Programa de Pós-Graduação em Ciências Florestais, Recife, Pernambuco - Brasil. E-mail: <licia@dcfl.ufrpe.br>,<marangon@dcfl.ufrpe.br $>$ e $<$ fernandojfreire@uol.com.br $>$.

${ }^{4}$ Universidade Federal de Campina Grande, Graduado em Agronomia, Pombal, Paraiba - Brasil. E-mail:<eniomholanda@hotmail.com>.
}

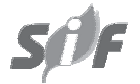

Revista Árvore, Viçosa-MG, v.39, n.2, p.245-254, 2015 http://dx.doi.org/10.1590/0100-67622015000200004 


\section{INTRODUÇÃO}

O Nordeste brasileiro é uma das regiões semiáridas mais habitadas do mundo (DRUMOND et al., 2008), e a principal formação vegetal presente nessa região é a Caatinga, considerada o único tipo de vegetação com os limites inteiramente restritos ao território nacional.

Segundo dados do Ministério do Meio Ambiente (Brasil, 2002), não há dúvida de que a Caatinga é um dos biomas brasileiros mais alterados pelas atividades humanas. É nessa região que estão localizadas as maiores áreas que passam por processo de desertificação. As causas das modificações são múltiplas e complexas e variam desde a exploração de madeira para combustível até a substituição da vegetação nativa por culturas agrícolas.

Para Lopes et al. (2009) e segundo Santana (2005), estudos sobre decomposição e liberação de nutrientes, direcionados a espécies da caatinga ou à própria caatinga, são praticamente inexistentes, o que contribui para o baixo nível de conhecimento e utilização de plantas do bioma, restringindo-se, assim, sua utilização econômica apenas ao extrativismo seletivo e contribuindo para sua degradação.

O conhecimento sobre a produção e decomposição da serapilheira e a forma de liberação de nutrientes é importante para se compreender o processo de ciclagem de nutrientes em ecossistemas florestais, e essas informações em áreas de Caatinga são bastante escassas ou não são publicadas (SOUTO, 2006).

O compartimento formado pela serapilheira e pelo solo é o sítio de todas as etapas da decomposição da matéria orgânica e da ciclagem de nutrientes, entretanto não significa que os diversos fenômenos envolvidos nesse processo ocorram exclusivamente nessa estreita porção do ambiente, pois, assim que o tecido vegetal é formado, começa a ocorrer sua decomposição (CORREIA; ANDRADE, 1999).

Parte do processo de retorno de matéria orgânica e de nutrientes para o solo florestal se dá através da produção de serapilheira, sendo esta considerada o meio mais importante de transferência de elementos essenciais da vegetação para o solo (VITAL et al., 2004). Além de ser fonte de nutrientes para os vegetais e microrganismos, a serapilheira permite maior retenção de umidade, evita erosão, melhora os atributos físicos do solo, entre outros.

Revista Árvore, Viçosa-MG, v.39, n.2, p.245-254, 2015
Segundo Regina (2001), a qualidade da matéria orgânica é muito importante para a maioria dos processos funcionais que ocorrem no solo, e a liberação de nutrientes da decomposição é importante via interna para o fluxo de nutrientes em ecossistemas florestais. A permanência da serapilheira na floresta fará que essa seja reaproveitada no ciclo de nutrientes do ecossistema, através de sua decomposição e da liberação dos elementos constituintes para posterior reabsorção pelas raízes (SCHUMACHER et al., 2003).

Para Cianciaruso et al. (2006), a produção e a decomposição de serapilheira são processos fundamentais para a manutenção da ciclagem de nutrientes, sendo este o aspecto mais estudado e geralmente associado com a quantificação dos nutrientes que retornam ao solo pela decomposição. Scheer (2008) descreveu que a decomposição da serapilheira resulta no acúmulo da matéria orgânica do solo, na liberação de seus nutrientes para a biota e na dissipação de parte do carbono, como dióxido de carbono, sendo um processo que mantém a fertilidade e a produtividade do sítio.

Paula et al. (2009) descreveram que a regulação das taxas de decomposição da matéria orgânica depende fundamentalmente das condições físicas e químicas do ambiente e da qualidade orgânica e nutricional do material que é aportado.

Diante do exposto, verificou-se que a decomposição dos resíduos vegetais é uma das etapas de grande importância no processo de ciclagem de nutrientes em ecossistemas florestais, pois parte do suprimento dos elementos que mantêm a estabilidade e a funcionalidade do sistema provém desse material.

Como a serapilheira é uma das principais fontes biológicas de nutrientes para vegetais e microrganismos presentes no solo e sua decomposição é uma etapa fundamental no ciclo biogeoquímico, é que este trabalho teve por objetivo analisar a decomposição do material foliar de 10 espécies que ocorrem na Caatinga, em consonância com a respiração edáfica em uma área de Caatinga localizada no interior da Paraíba.

\section{MATERIAL E MÉTODOS}

\subsection{Caracterização da área}

O estudo foi realizado em um remanescente de Caatinga localizado no Município de Pombal, PB. O 
fragmento tem uma área de 26,4 ha e está inserido entre as coordenadas geográficas $6^{\circ} 52^{\prime} 31^{\prime \prime}$ latitude Sul e $37^{\circ} 49^{\prime} 43^{\prime \prime}$ longitude Oeste. O clima da região, segundo a classificação de Köppen, é caracterizado como BSh (clima semiárido quente), com precipitação pluviométrica média anual mensurada nos últimos 10 anos de $963,07 \mathrm{~mm}$ (AESA, 2011) e temperatura média de $28{ }^{\circ} \mathrm{C}$. A área tem topografia ondulada, com altitudes entre $200 \mathrm{e}$ $230 \mathrm{~m}$. Os solos são classificados como Luvissolos em associação com Neossolos Litólicos (EMBRAPA, 2006).

\subsection{Coleta dos dados das medidas de perda de massa}

Para avaliar a taxa de decomposição das folhas e a liberação de nutrientes, foi utilizado o método de perda de massa em sacos de telas de náilon (litter bags). As bolsas foram confeccionadas com telas de náilon com malha de $1 \mathrm{~mm}^{2}$, com dimensões de $20 \mathrm{~cm}$ x 20 $\mathrm{cm}$. Em cada bolsa foram colocados $10 \mathrm{~g}$ de uma mistura das folhas secas das espécies, Croton blanchetianus, Combretum leprosum, Anadenanthera colubrina, Poincianella pyramidalis, Aspidosperma pyrifolium, Mimosa tenuiflora, Jatropha mollissima, Commiphora leptophloeos, Amburana cearensis e Myracrodruon urundeuva. Foram distribuídas em 12 unidades amostrais no local (amostragem da vegetação), 24 bolsas/parcela, totalizando 288 bolsas. As coletas foram realizadas em intervalos de 45 dias durante o período de um ano e, em cada unidade amostral, eram retiradas três litters bags/parcela.

Feito isso, o material foi encaminhado ao laboratório, seco a $65^{\circ} \mathrm{C}$, pesado e moído para a realização das análises químicas. Foram realizadas as análises do $\mathrm{N}$ e C total. $\mathrm{ON}$ foi determinado pelo método de Kjeldahl após a digestão sulfúrica, a determinação do $\mathrm{C}$ total foi baseada na oxidação da matéria orgânica em presença de ácido sulfúrico e dicromato de potássio (BEZERRA NETO; BARRETO, 2004).

\subsection{Coleta dos dados da respiração edáfica}

Para mensurar a respiração edáfica, utilizaram-se as mesmas parcelas e os mesmos períodos de avaliações das medidas de perdas de massa.

A metodologia adotada foi descrita por Grisi (1978), em que o $\mathrm{CO}_{2}$ desprendido do solo é absorvido por uma solução de $\mathrm{KOH}$ e, posteriormente, titulado com $\mathrm{HCl}$.

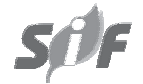

As áreas de amostragem utilizadas em cada medição do $\mathrm{CO}_{2}$ foram previamente limpas dos detritos orgânicos e da vegetação rasteira para colocação dos recipientes com a solução ( $10 \mathrm{~mL}$ de solução $\left.0,5 \mathrm{~mol} \mathrm{~L}^{-1} \mathrm{de} \mathrm{KOH}\right)$ sobre o solo. Esses recipientes (baldes), depois de destampados, foram cobertos imediatamente com baldes de PVC com 27,5 cm de diâmetro, cobrindo uma área do solo de $588 \mathrm{~cm}^{2}$, de forma que este permanecesse em contacto apenas com o ar proveniente do solo.

Foram utilizados em cada coleta 72 recipientes de vidro, cada um contendo $10 \mathrm{~mL}$ de solução, sendo 36 recipientes no período diurno (das $6 \mathrm{~h}$ às $18 \mathrm{~h}$ ) e 36 no noturno (das $18 \mathrm{~h}$ às $6 \mathrm{~h}$ ), totalizando $24 \mathrm{~h}$ de amostragem.

A quantificação do $\mathrm{CO}_{2}$ na solução de $\mathrm{KOH}$ foi feita a partir da titulação com solução-padrão ácida ( $\left.\mathrm{HCl} 0,1 \mathrm{~mol} \mathrm{~L}^{-1}\right)$, após a precipitação do íon carbonato presente nas amostras, inclusive nas amostras-controle (solução hermeticamente fechada, que permanece no laboratório).

\subsection{Análise da decomposição do material foliar e respiração edáfica}

A massa residual foi determinada em balança analítica com precisão de $0,01 \mathrm{~g}$, estimando-se a velocidade de decomposição ( $\mathrm{g} / 45$ dias) desse material em relação ao peso inicial $(10,0 \mathrm{~g})$. Com as informações do material foliar remanescente e os teores de $\mathrm{C}, \mathrm{Ne} \mathrm{C} / \mathrm{N}$, estimaramse a taxa de decomposição através de modelos de regressão que melhor se ajustassem aos dados.

Todas as médias tomadas nos intervalos de 45 dias da respiração edáfica, para os turnos (diurno e noturno), geral (entre o período) e a cada intervalo de dias, foram comparadas pelo teste $\mathrm{F}$ a $5 \%$ de probabilidade. As estimativas das análises de decomposição da massa de matéria seca foliar, teores de $\mathrm{C}, \mathrm{N}, \mathrm{C} / \mathrm{N}$ e respiração edáfica foram feitas com o auxílio do software Saeg.

\section{RESULTADO}

\subsection{Decomposição do material foliar}

A decomposição da serapilheira foi contínua e regular durante o período avaliado, em que o fator tempo, associado aos fatores microclimáticos e às ações dos microrganismos, teve influência no processo de decomposição, e a maior porcentagem das perdas de

Revista Árvore, Viçosa-MG, v.39, n.2, p.245-254, 2015 
massa da fração foliar foi registrada nos primeiros 45 dias, em que se verificou redução de 26,3\% (7,37 g), em comparação com o conteúdo inicial.

Constataram-se diferenças nas perdas de massa durante o período de avaliação, sendo a menor média registrada aos 360 dias, com uma massa remanescente de $32,9 \%$ (3,29 g), ou seja, nesse intervalo de tempo, $67,1 \%$ dos resíduos foliares, a princípio, foram decompostos pela ação dos microrganismos.

Em estudo semelhante realizado em área de Caatinga, Alves et al. (2006) observaram que, após 90 dias, a decomposição aumentou significativamente, restando 43,6\% dos resíduos utilizados. Pegado et al. (2009), verificando a decomposição foliar de quatro espécies da Caatinga, observaram que, quando comparados os diferentes locais que foram submetidos (Caatinga bem conservada - I e Caatinga em estado regular de conservação - II), no ambiente I, as espécies Croton blanchetinaus e Poincianella pyramidalis apresentaram maior taxa de decomposição, em que a pluviosidade teve influência marcante na taxa de decomposição inicial e a massa foliar das espécies com relação $\mathrm{C} / \mathrm{N}$ inferior a 30 apresentou maior taxa de decomposição.

Em outro tipo de vegetação, diferentemente da Caatinga, Cianciaruso et al. (2006), em um Cerradão no Município de Luiz Antonio, SP, verificaram que o processo de decomposição do material foliar ocorreu com maior intensidade nos primeiros meses, com perda de $33,6 \%$ da massa inicial, e nos meses subsequentes houve decomposição mais lenta e mais ou menos constante, e, ao final de um ano, $43 \%$ da massa original foi decomposta.

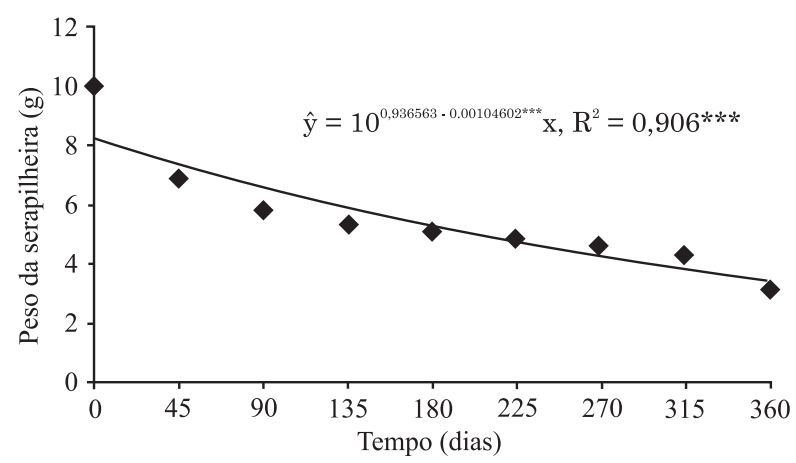

Figura 1 - Resíduos foliares remanescentes em razão do tempo em área de Caatinga no semiárido paraibano.

Figure 1 - Remaining leaf waste versus time in the semiarid Caatinga area of Paraíba.

Revista Árvore, Viçosa-MG, v.39, n.2, p.245-254, 2015
Nas concentrações de $\mathrm{C}$ total presentes na serapilheira foliar, verificou-se que seu teor diminuiu gradativamente ao longo do período, variando entre 288 e $180,8 \mathrm{~g} \mathrm{~kg}^{-1}$, ou seja, durante a decomposição foliar cerca de $37,2 \%$ do $\mathrm{C}$ presente no material foi dissipado para a atmosfera, ou utilizado pelos microrganismos durante o processo de respiração.

Pequeno acréscimo nas concentrações de $\mathrm{C}$ ocorreu a partir dos 270 dias e, provavelmente, por se tratar de mistura foliar, a princípio, as folhas que apresentavam maior proporção de $\mathrm{C}$ são mais resistentes ao processo de decomposição (remanescentes).

Com o N, percebe-se que há inconstância em suas concentrações ao longo do tempo, em que no tempo 0 é registrado seu maior teor $\left(22 \mathrm{~g} \mathrm{~kg}^{-1}\right)$. No intervalo entre 45 e 90 dias, percebe-se queda brusca na ordem de $34,7 \%$ e, a partir desse intervalo, constata-se que a concentração começa a aumentar, havendo diminuição novamente entre os últimos dias de avaliação (Figura 3).

$\mathrm{Na}$ relação $\mathrm{C} / \mathrm{N}$, verificou-se que seus valores variaram entre 18/1 (máximo) aos 90 dias e 10/1 (mínimo) aos 270 dias, ou seja, a diferença entre o maior e o menor teor em um intervalo de 180 dias foi de $44 \%$.

Valores superiores ao constatado neste trabalho para a relação $\mathrm{C} / \mathrm{N}$ foram verificados em área de Caatinga por Santana (2005) e Souto (2006), que encontraram 21,6 (mistura de folhas) e 32,9 (serapilheira total), respectivamente. Em área de Floresta Atlântica, Borem e Ramos (2002) verificaram uma relação 22/ 1, Scheer (2008) calculou uma relação 25,8 , Terror

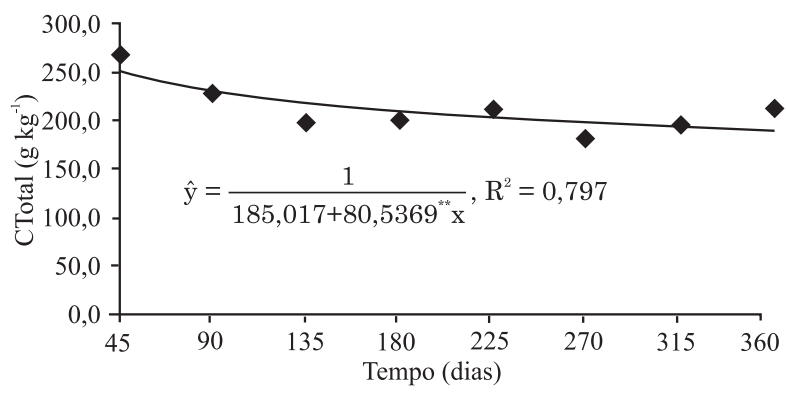

Figura 2 - Concentrações de carbono total na serapilheira foliar ao longo do tempo, em remanescente de Caatinga, no Município de Pombal, PB.

Figure 2 - Concentrations of total carbon in the leaf litter throughout time, in remainings of Caatinga, in the city of Pombal, PB. 


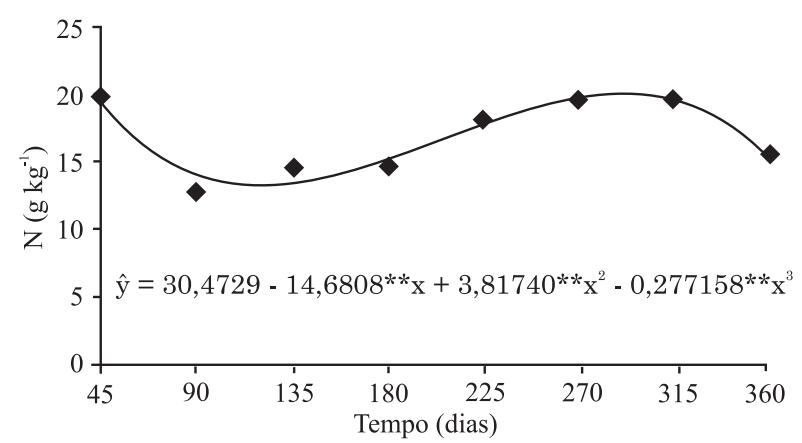

Figura 3 - Concentrações de N na serapilheira foliar, sob a superficie de um solo, em um fragmento de Caatinga, no interior da Paraíba.

Figure 3 -Concentrations of $N$ in the leaf litter beneath the surface of a soil in a fragment of Caatinga, in Paraíba.

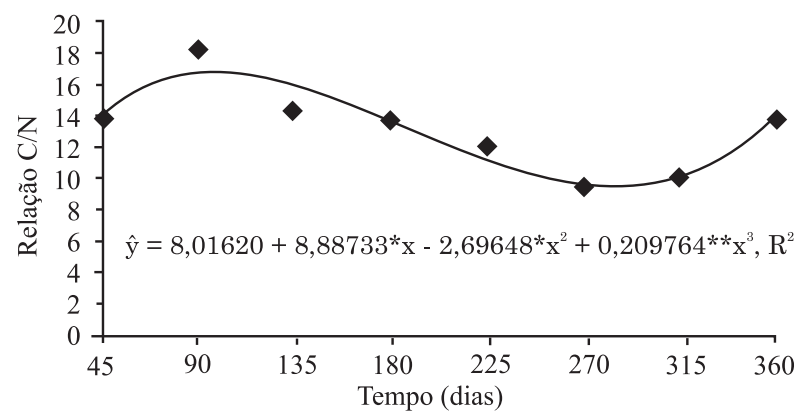

Figura 4 - Relação $\mathrm{C} / \mathrm{N}$ da serapilheira foliar em função do tempo, em área de caatinga, no Município de Pombal, PB.

Figure 4-Relationship C/N of leaf litter as a function of time, in an area of caatinga, in the city of Pombal, $P B$.

et al. (2011), em floresta paludosa, calcularam 44/1 e Dickow (2010), em área em sucessão secundária em Floresta Atlântica, verificou que a relação $\mathrm{C} / \mathrm{N}$ variou entre 20 e 60 .

\subsection{Respiração edáfica}

As médias da respiração edáfica nos turnos diurnos e noturnos apresentaram diferenças estatísticas, sendo o período noturno o que se encontra com os maiores valores de $\mathrm{CO}_{2}$ liberado, com 169,36 $\mathrm{mg} \mathrm{m}^{-2} \mathrm{~h}^{-1}$.

Ao analisar a influência da sazonalidade no desprendimento de $\mathrm{CO}_{2}$ durante os 360 dias de avaliação, verificou-se que existem diferenças entre os intervalos de dias, sendo a menor e maior média registradas aos 135 dias $\left(112,8 \mathrm{mg} \mathrm{m}^{-2} \mathrm{~h}^{-1}\right)$ e aos 225 dias $\left(176,7 \mathrm{mg} \mathrm{m}^{-2} \mathrm{~h}^{-1}\right)$, respectivamente.

Resultados semelhantes foram observados por Alves et al. (2006), em área de Caatinga, em que os autores constataram que houve diferença na produção de $\mathrm{CO}_{2}$ entre os turnos diurno e noturno, sendo maior no período noturno com $239,56 \mathrm{mg} \mathrm{m}^{-2} \mathrm{~h}^{-1}$. Silva et al. (2006), analisando a atividade microbiana em Luvissolo no semiárido, após a incorporação de resíduos vegetais, observaram que o período noturno teve a maior média de liberação de $\mathrm{CO}_{2} \operatorname{com} 385,78 \mathrm{mg} \mathrm{m}^{-2} \mathrm{~h}^{-1}$. Araújo et al. (2009), também em área de Caatinga, avaliando a produção de $\mathrm{CO}_{2}$ nos turnos diurno e noturno em dois períodos (Agosto/2007 e Março/2008), observaram maior desprendimento de $\mathrm{CO}_{2}$ no turno noturno em ambos os períodos, com 132,83 e $130,85 \mathrm{mg} \mathrm{m}^{-2} \mathrm{~h}^{-1}$, respectivamente. Em região semiárida, Benvinda (2005) verificou que a respiração noturna foi significativamente maior que a diurna, com $210 \mathrm{mg} \mathrm{m}^{-2} \mathrm{~h}^{-1}$.

Valores superiores aos observados em área de Caatinga foram obtidos por Santos e Crisi (1981), analisando os efeitos do desmatamento nas atividades dos microrganismos de solo de terra firme na Amazônia, em que verificaram maior liberação de $\mathrm{CO}_{2}$ em período noturno, e a área de capoeira após a derrubada e a queima apresentou valores de desprendimento de $\mathrm{CO}_{2}$ da ordem de $651,66 \mathrm{mg} \mathrm{m}^{-2} \mathrm{~h}^{-1}$, enquanto a capoeira, após a derrubada sem queima, e a floresta primária apresentaram valores de desprendimento de $\mathrm{CO}_{2}$ de 522,16 e $428,68 \mathrm{mg} \mathrm{m}^{-2} \mathrm{~h}^{-1}$, respectivamente.

Kepler et al. (1990), comparando a respiração do solo em área de mata natural, mata recém-queimada e área de pastagem, verificaram no trabalho (que tinha a finalidade de isolar a influência das camadas inferiores sobre a respiração total do solo), em mata primária, que $80 \%$ da respiração edáfica ocorreu nos primeiros $5 \mathrm{~cm}$ do solo, uma vez que a remoção da liteira pouco influiu na produção total de $\mathrm{CO}_{2}$. Segundo esses autores, a falta da contribuição das camadas superficiais foi compensada em $90 \%$ pela difusão de $\mathrm{CO}_{2}$ proveniente das camadas inferiores. Também, observaram que a liberação total de $\mathrm{CO}_{2}$ do solo para a atmosfera foi maior em área de pastagem, em comparação com a área de mata primária e área desmatada com posterior queimada. Em termos de porcentagem, a área de pastagem contribuiu com $50 \%$ a mais e a área desmatada e queimada contribuiu com $44 \%$ a menos que a área natural.

Revista Árvore, Viçosa-MG, v.39, n.2, p.245-254, 2015 
Tabela 1 - Liberação de $\mathrm{CO}_{2}$ nos turnos diurnos e noturnos em área de caatinga, no Município de Pombal, PB.

Table 1 - Release of $\mathrm{CO}_{2}$ in day and night shifts in an area of caatinga, in the city of Pombal, PB.

\begin{tabular}{|c|c|c|}
\hline \multirow[b]{2}{*}{ Fator } & \multicolumn{2}{|c|}{ Período } \\
\hline & $\begin{array}{c}\text { Diurno } \\
(\text { coleta às } 6 \mathrm{~h})\end{array}$ & $\begin{array}{c}\text { Noturno } \\
\text { (coleta às } 18 \mathrm{~h})\end{array}$ \\
\hline & $\mathrm{mg}$ & $\mathrm{h}^{-1}$ \\
\hline \multicolumn{3}{|l|}{ Tempo (dias) } \\
\hline 45 & $109,59 \mathrm{Ba}$ & $142,15 \mathrm{Db}$ \\
\hline 90 & $106,79 \mathrm{Ba}$ & $137,77 \mathrm{Db}$ \\
\hline 135 & $90,85 \mathrm{Ba}$ & $134,78 \mathrm{Db}$ \\
\hline 180 & $134,61 \mathrm{Aa}$ & $197,57 \mathrm{Bb}$ \\
\hline 225 & $143,85 \mathrm{Aa}$ & $209,55 \mathrm{Ab}$ \\
\hline 270 & $118,10 \mathrm{Aa}$ & $166,59 \mathrm{Cb}$ \\
\hline 315 & $123,47 \mathrm{Aa}$ & $171,88 \mathrm{Cb}$ \\
\hline \multirow[t]{2}{*}{360} & $130,50 \mathrm{Aa}$ & $194,64 \mathrm{Bb}$ \\
\hline & \multicolumn{2}{|r|}{ 19. } \\
\hline Tempo & \multicolumn{2}{|c|}{$15,3 * * *$} \\
\hline Período & \multicolumn{2}{|c|}{$181,62 * * *$} \\
\hline Tempo x Período & \multicolumn{2}{|c|}{$5,85 * * *$} \\
\hline C.V. $(\%)$ & \multicolumn{2}{|c|}{17,66} \\
\hline
\end{tabular}

\section{DISCUSSÃO}

\subsection{Decomposição do material foliar}

Existe uma série de fatores abióticos que influenciam no processo de decomposição do material foliar, e esses fatores ocorrem de forma subjetiva, quando se comparam diferentes áreas fitofisionômicas. Vale salientar que a qualidade do material vegetal é outro fator a ser considerado. Particularmente, em área de Caatinga, a decomposição do material foliar é relativamente lenta quando comparada a outros ecossistemas, principalmente devido à falta d'água, que é um componente importante e irá influenciar na concentração da umidade local, sendo vital ao processo de decomposição e multiplicação dos microrganismos.

Apesar de a decomposição da serapilheira ser favorecida pelo aumento da umidade do solo na maioria dos ecossistemas sazonais da região tropical, aparentemente existe um limite de saturação do solo a partir do qual o aumento na umidade passa a exercer um efeito semelhante ao ocasionado pelo déficit hídrico, reduzindo a velocidade com que a matéria orgânica depositada sobre o solo é decomposta (TERROR et al., 2011).

Naturalmente, é de se esperar que ao longo dos dias e em condições ambientais favoráveis ocorra redução nos teores dos elementos químicos presentes na serapilheira foliar, principalmente nos períodos em que são registrados maior umidade relativa e temperaturas mais elevadas, em que favorecerá a intensificação no processo de decomposição. Para Aduan et al. (2003), nas folhas está a principal via de entrada de C para o ecossistema, e o C proveniente da vegetação entra no solo pela queda do folhedo, do turnover das raízes e micorrizas e da exsudação de $\mathrm{C}$ pelas raízes finas. Em condições de equilíbrio, o ganho de C é compensado pelas perdas sob a forma de respiração heterotrófica dos decompositores do folhedo e da matéria orgânica do solo.

Comparando os dados observados neste trabalho com o de Aidar e Joly (2003), Costa et al. (2005), Santana (2005), Fernandes et al. (2006), Pereira et al. (2008), Scheer (2008), Pinto et al. (2009), Dickow (2010) e Terror et al. (2011), verificou-se semelhança, porém, sem que os teores de $\mathrm{N}$ ao longo do tempo se configurassem maior que o inicial, conforme observado por esses autores, que observaram que ao passar dos dias os teores de $\mathrm{N}$ aumentaram em relação ao conteúdo inicial e atribuíram esse aumento, em sua maior parte, à precipitação atmosférica, atividade de microrganismos que fixam N, e à contaminação; em alguns outros casos, esses autores citaram a concentração de compostos orgânicos produzidos, liberados e, ou, excretados pelos microrganismos decompositores.

A relação $\mathrm{C} / \mathrm{N}$ pode ser considerada como um dos grandes indicadores na taxa de decomposição da serapilheira, pois se sabe que, quanto maior o valor, maior o tempo para que os microrganismos presentes no solo levam para decompô-la. Estudos têm apontado que uma relação $\mathrm{C} / \mathrm{N}$ entre 20 e 30 é considerada adequada para as atividades microbianas, cujos nutrientes são mineralizados ou imobilizados. No entanto, se essa relação for abaixo desse valor, os nutrientes ficarão mais rapidamente disponíveis para as plantas.

Conforme observado nas relações $\mathrm{C} / \mathrm{N}$ deste estudo, verificou-se que estas se encontravam com valores baixos, o que implica dizer que, a princípio, existem condições ambientais favoráveis, e esse material será rapidamente mineralizado. Entretanto, Andrade et al. (2003) descreveram que, sob as mesmas condições pedoambientais, a velocidade de decomposição da serapilheira varia de acordo com a porcentagem de lignina, polifenóis, $\mathrm{C}, \mathrm{N}, \mathrm{P}$ e S, entre outros componentes.

Revista Árvore, Viçosa-MG, v.39, n.2, p.245-254, 2015 
Luz (2007) afirmou que a velocidade de decomposição dos materiais orgânicos é afetada pela composição bioquímica destes, porque os constituintes carbonatos precisam ser atacados inicialmente por enzimas extracelulares da microflora. Algumas dessas enzimas são produzidas por grande número de microrganismos, enquanto outras são produzidas por um número restrito de espécies microbianas.

Durante a decomposição de materiais orgânicos, os ciclos do $\mathrm{C}$ e do $\mathrm{N}$ no solo ocorrem com estreita relação, uma vez que a assimilação de $\mathrm{C}$ pelos microrganismos deverá ser acompanhada pela assimilação simultânea de N (LUZ, 2007).

\subsection{Respiração edáfica}

Uma das justificativas para a alta liberação de $\mathrm{CO}_{2}$ em período noturno está relacionada, a princípio, com a diminuição da temperatura nesse horário, o que pode levar a um aumento da umidade relativa e, consequentemente, propicia maior intensidade da atividade microbiana. Para Poggiani et al. (1977), a respiração edáfica está intimamente relacionada com as variações climáticas, principalmente com a temperatura e a pluviosidade.

Ao longo do período de avaliação, em apenas um mês não houve chuvas registradas no Município de Pombal, PB (junho de 2011), e o período que apresentou menores valores de precipitação pluviométrica compreenderam os intervalos de dias com os menores valores de desprendimento de $\mathrm{CO}_{2}$ pelo solo, chegando ao seu valor mais baixo aos 135 dias. Percebeu-se que os meses com as maiores liberações de $\mathrm{CO}_{2}$ coincidiram com o período de maiores acúmulos de chuvas, que contribuíram com o aumento da umidade no solo. Dessa forma, leva a crer que o fator água tem forte influência sobre o processo de liberação de $\mathrm{CO}_{2}$, o que a princípio está relacionado, principalmente, com o aumento da atividade microbiana no solo. Para Gama-Rodrigues (1999), a biomassa microbiana representa importante componente ecológico, pois é responsável pela decomposição e mineralização dos resíduos vegetais, utilizando esses materiais como fonte de nutrientes e energia para a formação e desenvolvimento de suas células, bem como para síntese de substâncias orgânicas no solo.

O que explicaria as diferenças estatísticas entre as coletas nos diferentes turnos, a princípio, está relacionado com a maior incidência solar durante todo o dia, que levou a um aumento em excesso da temperatura do solo que, consequentemente, inibiu em parte a atividade microbiana.

Segundo Souto et al. (2005), o ciclo secagem/ umedecimento do solo são bastante rápidos, o que pode implicar maior ou menor atividade e proliferação de organismos. Além disso, a temperatura superficial do solo mais elevada também contribui para a menor população microbiana e redução na intensidade de decomposição dos resíduos orgânicos.

Em seu estudo sobre a atividade microbiana em Luvissolo no semiárido da Paraíba após a incorporação de resíduos vegetais, Silva et al. (2006) verificaram que as maiores produções de $\mathrm{CO}_{2}$ estiveram associadas às maiores precipitações pluviométricas e no período noturno. Observaram também que, dos 60 aos 90 dias após a instalação do trabalho, ocorreu aumento na produção de $\mathrm{CO}_{2}$, podendo ser atribuído à maior atividade microbiana do solo, resultante das condições ideais do conteúdo de água e temperatura do solo para o desenvolvimento dos microrganismos, visto que, no referido período, a precipitação acumulada no mês atingiu valor de $138,7 \mathrm{~L} \mathrm{~m}^{-2}$.

Para outras formações florestais naturais e homogêneas em áreas úmidas, verificou-se que o comportamento é o mesmo da região semiárida, com maiores liberações de $\mathrm{CO}_{2}$ ocorrendo no turno noturno, porém, nessas áreas (úmidas), o desprendimento do $\mathrm{CO}_{2}$ é mais elevado.

Para Poggiani et al. (1983), de maneira geral, os valores de respiração são baixos em função da baixa temperatura e pequena atividade microbiológica do solo. Porém, em seu trabalho, observaram que no verão, com temperaturas mais elevadas e solo mais bem suprido em água, notaram considerável incremento na liberação de $\mathrm{CO}_{2}$ do solo, resultante da atividade biológica mais intensa. Ressaltaram, entretanto, que os valores diários obtidos não são constantes e ocorrem alterações intensas em função de variações da temperatura e da umidade do solo.

Silva et al. (2006) descreveram que vários fatores têm influência sobre o fluxo de $\mathrm{CO}_{2}$ para a superfície do solo, entre eles temperatura, umidade, profundidade do solo, aeração e populações microbianas.

Para Gama-Rodrigues et al. (2003), as interações dos fatores abióticos e bióticos, que regulam a funcionalidade dos ecossistemas florestais, atuariam 
positiva ou negativamente na velocidade de decomposição do folhedo das espécies florestais, mostrando, assim, que, mesmo em nível local, o processo de decomposição não seria influenciado apenas pela qualidade do substrato, mas também pela qualidade do microambiente.

Conforme observado, de modo geral, verificou-se que diversos fatores têm influência direta na liberação de $\mathrm{CO}_{2}$ do solo para a atmosfera, que vão desde a insolação, temperatura, umidade, índice pluviométrico, qualidade e quantidade da matéria orgânica, $\mathrm{pH}$, textura, porosidade, profundidade do solo, entre outros.

\section{CONCLUSÃO}

Em razão das condições climáticas a que o remanescente está submetido, pode-se inferir que a decomposição do material foliar foi relativamente rápida (aproximadamente $70 \%$ ), pois não foi observado acúmulo de serapilheira sobre a superfície do solo.

Pelo fato de a serapilheira foliar encontrar-se com baixa relação $\mathrm{C} / \mathrm{N}$, é um dos indicativos sobre a qualidade do material e sua facilidade no processo de decomposição, que é realizado pelos microrganismos, contribuindo rapidamente para o processo de mineralização.

A precipitação pluviométrica influenciou diretamente nas taxas de liberação de $\mathrm{CO}_{2}$ para a atmosfera, pois se verificou que os maiores valores desprendidos coincidiram com os maiores valores acumulados de chuvas.

A respiração edáfica foi mais intensa no período noturno, a princípio devido à diminuição da temperatura e ao aumento da umidade relativa, favorecendo os microrganismos no processo de decomposição da serapilheira.

\section{REFERÊNCIAS}

ADUAN, R. E.; VILELA, M. F.; KLINK, C.A.

Ciclagem de Carbono em

Ecossistemas Terrestres - O Caso do

Cerrado Brasileiro. Planaltina, DF: Embrapa

Cerrados, 2003. 30p. (Documentos, 105).

AESA -Agência executiva de gestão das águas do estado da Paraíba. Monitoramento de chuvas acumuladas. Disponível em: <http:// http://site2.aesa.pb.gov.br/aesa/

Revista Árvore, Viçosa-MG, v.39, n.2, p.245-254, 2015
monitoramentoPluviometria.do?metodo=listarChuvas AnuaisAtual>. Acesso em 04 de abril de 2011.

AIDAR, M.P.M.; JOLY, C.A. Dinâmica da produção e decomposição da serapilheira do araribá (Centrolobium tomentosum Guill. ex Benth. - Fabaceae) em uma mata ciliar, Rio JacaréPepira, São Paulo. Revista Brasileira de Botânica, v.26, n.2, p.193-202, 2003.

ALVES, A. R.; SOUTO, J. S.; SOUTO, P. C.; HOLANDA, A. C. Aporte e decomposição de Serapilheira em área de Caatinga, na Paraíba. Revista de Biologia e Ciências da Terra, v.6, n.2, p.194-203, 2006.

ANDRADE, A.G.; TAVARES, S.R.L.; COUTINHO, H.L.C. Contribuição da serapilheira para recuperação de áreas degradadas e para manutenção da sustentabilidade de sistemas agroecológicos. Informe Agropecuário, v.24, n.220, p.55-63, 2003.

ARAÚJO, K.D.; PARENTE, H.N.; CORREIA, K.G.; DANTAS, R.T.; ANDRADE, A.P.; PAZERA JUNIOR, E. Liberação de dióxido de carbono $\left(\mathrm{CO}_{2}\right)$ em área de Caatinga no semiárido da Paraíba. Geoambiente, n.12, p.42-53, 2009.

BENVINDA, J.M.S. Decomposição de resíduos de Nim (Azadiractha indica) em agroecossistemas no semiárido da Paraíba. 2005. 58f. Dissertação (Mestrado em Zootecnia) - Universidade Federal de Campina Grande, Patos, 2005.

\section{BEZERRA NETO, E.; BARRETO, L.P. Métodos} de análises químicas em plantas. Recife: UFRPE, Imprensa Universitária. 2004. 165p.

BOREM, R.A.T.; RAMOS, D.P. Variação estacional e topográfica de nutrientes na serapilheira de um fragmento de Mata Atlântica. Cerne, v. 8, n.2, p.042-059, 2002.

BRASIL. Ministério do Meio Ambiente.

Avaliação e ações prioritárias para a conservação da biodiversidade da Caatinga. Recife: Universidade Federal de Pernambuco, Fundação de Apoio ao Desenvolvimento, Fundação Biosiversitas, Embrapa/ Semi-Árido, MMA/SBF, 2002.36p.

CIANCIARUSO, M.V.; PIRES, J.S.R.; DELITTI, W.B.C.; SILVA, E.F.L.P. Produção de serapilheira e 
decomposição do material foliar em um cerradão na Estação Ecológica de Jataí, município de Luiz Antônio, SP, Brasil. Acta Botânica

Brasílica. v.20, n.1, p.49-59, 2006.

CORREIA, M. E. F.; ANDRADE, A. G. Formação da Serapilheira e ciclagem de nutrientes. In: SANTOS, G. A.; CAMARGO, F. A. O (Ed.). Fundamentos da matéria orgânica do solo: ecossistemas tropicais e subtropicais. Porto Alegre: Genesis, 1999. p.197-225.

COSTA, G.S.; GAMA-RODRIGUES, A.C.; CUNHA, G.M. Decomposição e liberação de nutrientes da serapilheira foliar em povoamentos de Eucalyptus grandis no Norte Fluminense.

Revista Árvore, v.29, n.4, p.563-570, 2005.

DICKOW, K.M.C. Ciclagem de fitomassa e nutrientes em sucessão secundária na Floresta Atlântica, Antonina, PR. 2010. 215f. Tese (Doutorado em Engenharia Florestal), Universidade Federal do Paraná, Curitiba, 2010.

DRUMOND, M. A.; PIRES, I. E.; OLIVEIRA, V. R.; OLIVEIRA, A. R.; ALVAREZ, I. A. Produção e distribuição de biomassa de espécies arbóreas no Semi-Árido Brasileiro. Revista Árvore, v.32, n.4, p.665-669, 2008.

EMPRESA BRASILEIRA DE PESQUISA AGROPECUÁRIA - EMBRAPA. Sistema brasileira de classificação de solos. 2.ed. Rio de Janeiro: Embrapa solo. 2006. 306 p.

FERNANDES, M.M.; PEREIRA, M.G.; MAGALHÃES, L.M.S.; CRUZ, A.R.; GIÁCOMO, R.G. Aporte e decomposição de serapilheira em áreas de floresta secundária, plantio de Sabiá (Mimosa caesalpiniaefolia Benth.) e Andiroba (Carapa guianensis Aubl.) na Flona Mário Xavier, RJ. Ciência Florestal, v.16, n.2, p.163$175,2006$.

GAMA-RODRIGUES, E.F. Biomassa microbiana e ciclagem de nutrientes. In: SANTOS, G. A.; CAMARGO, F. A. O (Ed.). Fundamentos da matéria orgânica do solo: ecossistemas tropicais e subtropicais. Porto Alegre: Genesis, 1999. p.227-243.

GAMA-RODRIGUES, A.C.; BARROS, N.F.; SANTOS, M.L. Decomposição e liberação de nutrientes do folhedo de espécies florestais nativas em plantios puros e mistos no sudeste da Bahia. Revista Brasileira de Ciência do Solo, v.27, n.6, p.1021-1031, 2003.

GRISI, B.M. Método químico de medição da respiração edáfica: alguns aspectos técnicos. Ciência e Cultura, v.30, n.1, p.82-88, 1978.

KEPLER, S.; VOLKOFF, B.; CERRI, C.C.; CHONE, T.; LUIZÃO, F.; EDUARDO, B.P. Respiração do solo: comparação entre áreas com mata natural, mata recém-queimada e pastagem, na Amazônia central. Geochimica Brasiliensis, v.4, n.2, p.111$118,1990$.

LOPES, J.F.B.; ANDRADE, E.M.; LOBATO, F.A.O.; PALÁCIO, H.A.Q.; ARRAES, F.D.D. Deposição e decomposição de serapilheira em área da Caatinga. Revista Agroambiente, v.3, n.2, p.72-79, 2009.

LUZ, L.P. Dinâmica do carbono durante a decomposição de palha de trigo marcada com ${ }^{13}$ e dejetos líquidos de suínos. 2007. 72f. Dissertação (Mestrado em Ciência do Solo) - Universidade Federal de Santa Maria, Santa Maria, 2007.

PAULA, R.R.; PEREIRA, M.G.; MENEZES, L.F.T. Aporte de nutrientes e decomposição da serapilheira em três fragmentos florestais periodicamente inundados na Ilha da Marambaia, RJ. Ciência Florestal, v.19, n.2, p.139-148, 2009.

PEGADO, C. M. A.; SOUTO, J. S.; PEREIRA, W. E.; FÉLIX, L. P.; DANTAS JUNIOR, O. R.

Decomposição foliar de quatro espécies da Caatinga na região de Santa Terezinha, Paraíba.

Revista Acta Tecnológica, n.3, p.15-27, 2009.

PEREIRA, M.G.; MENEZES, L.F.T.; SCHULTZ, N. Aporte e decomposição da serapilheira na floresta atlântica, Ilha da Marambaia, Mangaratiba, RJ.

Ciência Florestal, v.18, n.4, p.443-454, 2008.

PINTO, S.I.C.; MARTINS, S.V.; BARROS, N.F.; DIAS, H.C.T. Ciclagem de nutrientes em dois trechos de floresta estacional semidecidual na reserva florestal mata do paraíso em Viçosa, MG, Brasil. Revista Árvore, v.33, n.4, p.653-663, 2009.

POGGIANI, F.; LIMA, W.P.; BALLONI, E.A.; NICOLIELLO, N. Respiração edáfica em

Revista Árvore, Viçosa-MG, v.39, n.2, p.245-254, 2015 
plantações de coníferas e folhosas exóticas em área de cerrado do estado de São Paulo. IPEF, n.14, p.129-148, 1977.

POGGIANI, F.; REZENDE, G.C.; SUITER FILHO, W. Efeitos do fogo na brotação e crescimento de Eucalyptus grandis após o corte raso e alterações nas propriedades do solo. IPEF, n.24, p.33-42, 1983 .

REGINA, I.S. Litter fall, decomposition and nutrient release in three semi-arid forests of the Duero basin, Spain. Forestry, v.74, n.4, p.347358, 2001.

SANTANA, J. A. S. Estrutura fitossociológica, produção de serapilheira e ciclagem de nutrientes em uma área de Caatinga no Seridó do Rio Grande do Norte. 2005. 206f. Tese (Doutorado em Agronomia) - Universidade Federal da Paraíba, Areia, 2005.

SANTOS, O.M.; CRISI, O.M. efeitos do desmatamento nas atividades dos microorganismos de solo de terra firme na Amazônia. Acta Amazônica, v.11, n.1, p.97102,1981

SCHEER, M. B. Decomposição e liberação de nutrientes na serapilheira foliar em um trecho de Floresta Ombrófila Densa Aluvial em regeneração, Guaraqueçaba (PR). Revista Floresta, v. 38, n. 2, p.253-266, 2008

SHUMACHER, M.V.; BRUN, E.J.; RODRIGUES, L.M.; SANTOS, E.M. Retorno de nutrientes via deposição de serapilheira em um povoamento de acácia-negra (acacia mearnsii de wild.) no estado do Rio Grande do Sul. Revista Árvore, v.27, n.6, p.791-798, 2003.

SILVA, G.A.; SOUTO, J.S.; ARAUJO, J.L. Atividade microbiana em Luvissolo do semiárido da Paraíba após a incorporação de resíduos vegetais. Agropecuária Técnica, v.27, n.1, p.13-20, 2006.

SOUTO, P. C. Acumulação e decomposição da serapilheira e distribuição de organismos edáficos em área de Caatinga na Paraíba, Brasil. 2006. $161 \mathrm{f}$.

Tese (Doutorado em Solos e Nutrição de Plantas) Universidade Federal da Paraíba, Areia, 2006.

SOUTO, P.C.; SOUTO, J.S.; SANTOS, R.V.; ARAÚJO, G.T.; SOUTO, L.S. Decomposição de estercos dispostos em diferentes profundidades em área degradada no semiárido da Paraíba.

Revista Brasileira de Ciência do Solo, v.29, n.1, p.125-130, 2005.

TERROR, V.L.; SOUSA, H.C.; KOSOVITS, A.R. Produção, decomposição e qualidade nutricional da serapilheira foliar em uma floresta paludosa de altitude. Acta Botanica Brasílica, v.25, n.1, p.113-121, 2011.

VITAL, A. R.T.; GUERRINI, I.A.; FRANKEN, W.K.; FONSECA, R.C.B. Produção de serapilheira e ciclagem de nutrientes de uma floresta estacional semidecidual em zona riparia. Revista Árvore, v.28, n.6, p.793-800, 2004. 